\title{
Editorial
}

\section{Live surgical workshops: Educational or vain glitz}

here is no doubt in my mind that it's vital to share knowledge and experiences with peers in the medical fraternity. Live surgeries offer educational value and live surgical workshops have become very common throughout the span of the surgical field. However, are we not making this look far more sensational in its 'live' avatar? Why shouldn't the same surgery be presented as a properly edited video, taped while the operator was operating in his own operating environment? Will that not be far safer for both patient and the surgeon? Will that not be far more value for time for the viewing trainees and delegates and lastly will that not be far more ethical for the surgical fraternity? Are we on to something more educational or are we promoting something more sensational?

Using web conferencing as a tool, beaming live surgeries has become one of the most attractive and efficient way to demonstrate, explain and teach surgical or medical techniques to an audience of peers watching it from various locations, often continents apart! In a country like India it is argued that this opportunity brings the rural surgeons closer to their urban peers. This exercise provides a dynamic educational platform for the audience through which knowledge is shared by the experts performing these surgeries with first hand visuals of the operation and the two-way communication with the participants during the live procedures. As participants get an opportunity to observe the live procedure with decisions taken on real time, they are also exposed to unexpected challenges and other unforeseen intricacies of a surgery. However, it is from these unforeseen and unexpected challenges that my objections to these live surgical workshops take birth.

\begin{tabular}{|l|l|}
\hline \multicolumn{2}{|c|}{ Access this article online } \\
\hline Quick Response Code: & Website: \\
\hline & www.ijps.org \\
\cline { 2 - 2 } & Dol: \\
\hline & $10.4103 / 0970-0358.121926$ \\
\hline
\end{tabular}

The value of video images in disseminating surgical knowledge is immense and unequivocally true, but why 'live' broadcasts? Supporters for these programmes argue that a live telecast somehow brings energy, honesty and the drama and teaches the audience to deal with unexpected complications. However, at the same time this brings sensationalism and thrill at the expense of the helpless patient.

The conference organizers today make the 'live demonstration' the main focus to promote a meeting and create a lot of hype around it. The audience is promised 'a visual treat' and the delegates come with the main intention of watching surgical feats on a big screen. The entire focus of a conference often shifts to the live workshop sessions and there is hardly any audience for the panel discussions and papers. In fact, it is not uncommon for conference organisersto cancel other events when the live operative sessions overshoot the scheduled time. However, it is time to ask a pertinent question - is this visual treat doing any good to anybody? There are three parties involved in this interaction - the visiting surgeon, the learning audience and most certainly patient. Let us analyse with a cool mind who is being benefitted.

\section{THE VISITING SURGEON}

He/she has come from a distant land tired and jet lagged he often sees patient for the first time in the pre-operative room, although if he was delivering a prior lecture, he might not be even that lucky and the patient may be anaesthetized well before he arrives in the operating theatre. So the pre-operative planning is discussed on still photographs or on a sleeping patient lying supine with no inputs from him/her. Even if he has an opportunity to interact with patient due to language difficulties, he has very little chance of making a clinical assessment of the indication for the procedure. In the OR, an overseas surgeon invariably finds himself in an alien environment, with an unfamiliar bunch of assistants, inexperienced in assisting the proposed surgery and a less than optimal set of instruments, simply because they are not his own. 
Talking while operating can divert the attention of the surgeon, but this is what he plans to do throughout the surgery! He knows that the physician in him should avoid situations that put patient at risk of harm, but does he have a choice? If multi-tasking is prohibited for mundane tasks like driving, why should it be allowed for more demanding tasks like surgery? It has already been proven that accidents are often caused while talking over a mobile phone. How is a microphone different from a mobile phone in this context? Is sensationalism not overtaking professionalism here?

If a suitable patient or implant was not arranged by the organisers even then the visiting surgeon is under pressure to 'deliver' because he has been touted as an expert and that is exactly what the audience is expecting him to do! He also has his own set of pre-operative preparations and post-operative instructions and he knows fully and teaches repeatedly that both are vital for the success of his surgery, but chances are that he will not be around to monitor either! How many experts have declined to do a procedure because they cannot see a good indication when confronted with patient on the table and an expectant audience? How many experts check on key environmental factors that they take for granted at home - such as local practices for disinfection, antibiotic prophylaxis, sedation and monitoring. If it appears that the local practices are different, should the surgeon insist on his own standards or bend them for the benefit of 'the show'? Can a teacher and an expert afford to make these compromises? Again are all decisions in live surgery workshops taken in the best interests of patient? It is possible that the operating surgeon feels compelled to continue with an operation as it has been advertised by the organizers. So is this live surgical workshop good for the visiting surgeon?

\section{THE AUDIENCE}

The argument that such workshops fill the void created by the inability of postgraduate training programmes to expose students to new operative techniques has its limitations since these workshops are a poor alternative to structured teaching. The planning session with patient in these workshops is either missing or unstructured and anaemic and a detailed discussion on the indications, pre-operative preparation, investigations, post-operative care as well as complications is hardly ever taking place.
Walker and Peyton ${ }^{[1]}$ of the Royal College of Surgeons has popularized the four steps to effective learning of procedural skills:

- Demonstration: Trainer demonstrates at normal speed, without commentary

- Deconstruction: Trainer demonstrates while describing steps

- Comprehension: Trainer demonstrates while learner describes steps

- Performance: Learner demonstrates while learner describes steps.

This four step approach ensures that the teacher breaks the process into manageable steps and progress is made from one stage to the next as each step is mastered. Watching a master surgeon demonstrate his/her art is only one step in the process of learning. Divorcing the first step from the subsequent three, whilst may be useful for the few experienced senior surgeons in the audience, can have disastrous consequences for the more junior inexperienced surgeons and their patients. There is a serious danger of some degree of oversimplification of the operative process as, often in well-organised workshops, well-selected patients are operated upon by the best surgeons with the best of equipment and back-up. It is not uncommon therefore to hear of how surgeons try to emulate a certain procedure they have recently observed in a workshop and how the first two post-workshop weeks become most disaster prone for a young and impressionable surgeon. And finally, who all are sitting in the audience? Are you sure tomorrow you will not complain that after a weekend workshop on liposuction your neighbouring dentist has now become a body contour specialist? So is this experience good for the training audience?

\section{THE PATIENT}

Is the patient clearly told that she/he will be the subject of a 'live' demonstration by a visiting faculty in front of a large audience? Does he/she know that the operating surgeon is unlikely to be available to deal with postoperative complications if they arise? How often does the visiting surgeon himself explain the procedure to the patient and family? Are the principles of a proper informed consent respected in the setting of such live workshops? Is the patient made aware of the fact that the surgeon may be tired after a long flight, harassed by a new band of assistants, hassled by unfamiliar set 
of instruments and constantly talking to an ever eager audience while operating upon him/her? Is it all right with him/her that he/she is not getting the surgeon's $100 \%$ attention, which he/she deserves?

In live surgeries, patient details are announced and patients seen by more people than they may be comfortable with. Often, a patient may feel coerced to consent as otherwise a foreign surgeon/expert may not operate, but is he/she prepared to share his/her medical condition and grief with a hall full of aliens? I have seen overseas surgeons purchasing drills and bits from hardware stores in developing countries and using them in surgery the next day. Was the patient informed about such innovations while obtaining the consent for surgery? So are these live workshops good for patients?

It is also no coincidence that this boom of live surgical workshops has come at a time when technology has entered surgery in a big way; the best examples being the fields of implantology, endoscopy and laparoscopy. A huge and ever-growing medical equipment industry provides the main funds for these workshops as for them it is a ready-made opportunity to display and promote their gadgets and wares. Often, the unwritten tradeoff for such funding is the promise of subtle promotion through the medium of the workshop. It can also not be denied that these workshops are essentially a part of a grand marketing strategy for many 5 star hospitals and corporate institutes. Thus, the form and content is often designed to promote the host institution or a particular procedure or equipment or even an individual, rather than representing a well thought out scientific and educational activity. There are a variety of factors that create the background for a certain compulsion on one hand for the organisers and on the other, for the visiting surgeon to 'perform' the procedure in front of an expectant audience and it takes a great deal of courage and conviction for most people to resist such pressure, which has the potential of transgressing both science and ethics.

So what is a better alternative? Edited videos - it would be better for the procedure to be recorded and replayed frame by frame. The surgeon will be in a better position to explain the procedure after it has been completed. However, in edited videos, most experts would gloss over mistakes or difficulties and there lies the human factor in a teacher. Telemedicine, with operations performed by persons in their own environment, is an excellent option but may be beyond the reach of many institutions today. Too often, live surgery contains endless stretches of technical details that have little educational merit. Technical difficulties, delays in the procedure itself and problems with audio-video signal feed add to the chaos. Isn't a well-edited surgical video, with narration and figures, added later by the surgeon, after thoughtful review, a far better alternative. It saves time and teaches more and protects both the surgeon and his patient.

\section{Surajit Bhattacharya} Editor Indian Journal of Plastic Surgery E-mail: sorajitbh@yahoo.co.in

\section{REFERENCE}

1. Walker M, Peyton JW. Teaching in theatre. In: Peyton JW, editor. Teaching and Learning in Medical Practice. Rickmansworth, UK: Manticare Europe Ltd.; 1998. p. 171-80.

How to cite this article: Bhattacharya S. Live surgical workshops: Educational or vain glitz. Indian J Plast Surg 2013;46:453-5.

Announcement

\section{“QUICK RESPONSE CODE” LINK FOR FULL TEXT ARTICLES}

The journal issue has a unique new feature for reaching to the journal's website without typing a single letter. Each article on its first page has a "Quick Response Code". Using any mobile or other hand-held device with camera and GPRS/other internet source, one can reach to the full text of that particular article on the journal's website. Start a QR-code reading software (see list of free applications from http://tinyurl.com/yzlh2tc) and point the camera to the QR-code printed in the journal. It will automatically take you to the HTML full text of that article. One can also use a desktop or laptop with web camera for similar functionality. See http://tinyurl.com/2bw7fn3 or http://tinyurl.com/3ysr3me for the free applications. 